\title{
O Discurso da Institucionalização de Práticas em Saúde: uma reflexão à luz dos referenciais teóricos das ciências humanas
}

\section{| ${ }^{1}$ Auristela Maciel Lins, ${ }^{2}$ Luiz Carlos de Oliveira Cecilio |}

Resumo: O objetivo deste artigo é promover uma reflexão sobre o discurso da institucionalização de práticas de saúde, notadamente da avaliação, e em que medida ela pode levar à mudança pretendida, ou, por outro lado, reafirmar conceitos enraizados e reproduzir práticas. Para isto, se buscou auxílio nos teóricos do campo das ciências humanas, principalmente aqueles que têm refletido sobre as instituiçôes sociais. Os referenciais teóricos utilizados são de autores da sociologia positivista, da fenomenologia sociológica e do movimento institucionalista francês. Com eles, busca-se compreender a noção de instituição presente nessas escolas e seu reflexo na concepção de institucionalização. À luz do referencial no qual se apóiam, os autores sugerem alguns cuidados na condução prática das ações que apóiam o movimento da institucionalização da avaliação em saúde.

Palavras-chave: avaliação; institucionalização; serviços de saúde; políticas de saúde; ciências sociais.

\author{
${ }^{1}$ Agência Nacional de \\ Vigilância Sanitária - ANVISA e \\ Universidade de Brasília, \\ professora voluntária, doutora \\ em Saúde Coletiva. Endereço \\ eletrônico: auristela@unb.br \\ ${ }^{2}$ Departamento de Medicina \\ Preventiva, Universidade \\ Federal de São Paulo, professor \\ adjunto, doutor \\ em Saúde Coletiva. Endereço \\ eletrônico: \\ cecilioluiz@uol.com.br
}

Recebido em: 14/12/2006. Aprovado em: 03/09/2007. 


\section{Introdução}

Este artigo tem como ponto de partida uma reflexão sobre o que poderia ser denominado de "discurso da institucionalização da avaliação". Um dos autores do presente artigo vivenciou um trabalho de três anos junto ao Departamento de Atenção Básica do Ministério da Saúde, durante o qual, cotidianamente, se expressava a preocupação com a institucionalização das práticas de avaliação da Atenção Básica no país.

Com a institucionalização da avaliação como problema da vida prática, principalmente com o significado atribuído ao termo "institucionalização" por autores do campo da avaliação em saúde, nossa atenção ficou voltada para o que se produzia teórica e praticamente com o propósito explícito de "institucionalizar", seja na área da saúde ou fora dela. A busca pelos termos "institucionalizar" e “institucionalização" na literatura da América Latina e Caribe, por meio do Lilacs, nos apresenta uma variedade muito grande de artigos com o tema. Muitos deles se referem à institucionalização como a estada de pessoas em instituições de longa permanência, como asilos, hospitais psiquiátricos, escolas ou creches. Essa produção é extensa e trata do binômio institucionalização/desinstitucionalização com diversas abordagens teóricas.

Por outro lado, quando a literatura é mais técnica e voltada à orientação das ações e das políticas de saúde mais especificamente (artigos, comunicações e informes técnicos), constata-se que, de forma geral, não há preocupação em explicitar um conceito para "institucionalização" (HARTZ, 1999 e 2002; BRASIL, 2005 e 2006) ou apenas o explicitam com sua face "operacional" (FELISBERTO, 2006).

Aliás, é esta face "operacional" que revela um dos melhores exemplos da aparente tendência à adoção, por parte de destacados dirigentes e intelectuais da saúde, do discurso da "institucionalização". O volume 11, número 3 do ano de 2006 da revista Ciência \& Saúde Coletiva foi o que nos desencadeou a importância de promover um debate sobre a institucionalização e de como um termo com uma carga conceitual muito presente nas ciências sociais vem sendo utilizado em outros campos do conhecimento. Nesse número da revista o articulista (FELISBERTO, 2006) e os debatedores (CONILL, 2006; PISCO, 2006; TAKEDA; TALBOT, 2006; TANAKA, 2006; TEIXEIRA, 2006) discorrem sobre a importância da avaliação em saúde e sua institucionalização. 
A revista Ciência \& Saúde Coletiva dedica esse número temático à publicação de vários artigos decorrentes do amplo estudo de linha de base da atenção básica (ELB) realizada em 2005, em todos os municípios brasileiros com mais de cem mil habitantes, projetos de pesquisa fomentados pelo Departamento de Atenção Básica do Ministério da Saúde e Banco Mundial. Os estudos de linha de base (ELB) se caracterizaram como um dos focos de intervenção das ações da Política Nacional de Avaliação da Atenção Básica. O número se inicia pela exposição de Felisberto e pelo debate de suas idéias pelos autores citados.

$\mathrm{O}$ autor já explicita no resumo que o artigo propõe uma reflexão teórica e operacional, a ser enriquecida pelos debatedores convidados, sobre o significado de institucionalizar a avaliação a partir da perspectiva do gestor federal em induzir um "aculturamento" da avaliação na rotina da atenção básica, considerada ação norteadora de uma política de saúde. (FELISBERTO, 2006, p. 553).

Exceto por questôes levantadas por um dos debatedores (TANAKA, 2006), o conceito de "institucionalização" utilizado pelo autor não foi problematizado pelos demais debatedores. As reflexôes do autor e dos demais debatedores centram-se na face "operacional" da proposta, o que poderíamos designar como uma "postura pragmática” no debate sobre avaliação. Apontamos, no presente artigo, algumas considerações teóricas que podem iluminar o tema da avaliação sob outros ângulos, em particular as contribuições dos autores do movimento institucionalista francês, com destaque para os trabalhos de René Lourau e George Lapassade.

É importante ressaltar o enorme esforço de construção conceitual e de mobilização dos conhecimentos das disciplinas que convergem para a avaliação em saúde e para a atenção básica que transparece no conjunto dos artigos apresentados nesse número especial e, naturalmente, o esforço operacional que lhes deu sustentação. No entanto, da citada revista só nos ateremos ao debate explicitado por Felisberto e os autores debatedores, pois se deseja apenas trazer à tona o discurso institucionalizador exemplificado no artigo de Felisberto. Os demais artigos relatam os resultados da vasta pesquisa de linha de base realizada no país em 2005, conforme já explicitamos.

Qual a importância do significado atribuído ao termo "institucionalização" para auxiliar a resolução dos problemas da vida prática? Esta é a discussão que pretendemos iniciar neste artigo, trazendo autores de algumas correntes das ciências humanas que discutem o conceito de instituição e seu decorrente, institucionalização. 
Hoje não se pode mais falar da incipiência da produção teórica da avaliação no país. Produz-se de forma muito significativa em relação à avaliação de serviços, avaliação de programas, avaliação de atividades, avaliação de políticas sociais e outros enfoques. Acredita-se que um indicador da importância dada à avaliação em saúde é a transição da preocupação puramente acadêmica para a preocupação com a prática avaliativa, com a avaliação realizada na prática de saúde pelos profissionais que planejam, gerenciam e exercem as atividades de saúde no cotidiano. Vive-se o momento da transição dos "escritórios de avaliação", ou seja, da avaliação sendo feita por avaliadores isentos e descompromissados com os produtos e resultados de seus relatórios de avaliação (sejam esses avaliadores externos ou internos), para o momento do "avalia quem faz e faz quem avalia", parodiando Matus (1987).

Há, nitidamente, a preocupação de consolidar a avaliação como um instrumento de gestão da mudança. Assim, a preocupação deste artigo é contribuir com a reflexão sobre os significados atribuídos à institucionalização de forma geral e, em particular, à institucionalização da avaliação nas práticas de saúde e, em que medida ela pode levar à mudança pretendida, ou, por outro lado, pode reafirmar conceitos enraizados e reproduzir práticas.

\section{A noção de instituição presente em algumas correntes das ciências sociais}

A origem do termo é o latim, vem de instituere, que significa colocar em; estabelecer, construir, preparar, fundar, regulamentar. Etimologicamente, significa a coisa estabelecida, portanto.

No entanto, Barbier (1985) e Lourau (1996) chamam a atenção para a imprecisão do conceito no uso cotidiano. De forma mais geral e mais comum, o termo instituição designa um estabelecimento, como um hospital ou uma escola. As pessoas comumente se referem a esses estabelecimentos como "a instituição na qual trabalho" ou "a instituição com a qual me relaciono". Os autores citados e outros do chamado "movimento institucionalista" (BAREMBLIT, 1996; LAPASSADE, 1989) alertam, no entanto, para outras formas materiais, mais complexas, chamadas de instituição ou outras formas organizativas não-materiais que também são chamadas de instituição, como a instituição da justiça, da honra, do trabalho, do parentesco, etc. 
Por que essa mesma designação para diferentes entes sociais? Lourau (1996) mostra a evolução do conceito através dos séculos e Barbier (1985) apropria-se de suas reflexões para contextualizar o trabalho da pesquisa-ação na instituição educativa. Para esses autores, a noção de instituição vai se modificando na medida em que os indivíduos vão se tornando sujeitos da história e da construção social. Para o movimento institucionalista francês, do qual os autores citados fazem parte, o conceito de instituição é constituído por três momentos: i) o momento da universalidade, tendo por conteúdo os sistemas de normas, os valores que orientam a socialização, a ideologia, o instituído, enfim; ii) o momento da particularidade, no qual seu conteúdo se resume às determinações materiais e sociais que negam a universalidade, dada no primeiro: é o momento instituinte; iii) o momento da singularidade, de negação da particularidade, em que o conceito de instituição tem por conteúdo as formas organizacionais, jurídicas ou anônimas necessárias para atingir determinado objetivo ou determinada finalidade - é o momento da institucionalização (LOURAU, 1996).

Nessa evolução e na dependência da corrente de pensamento mais em evidência, um desses momentos do conceito - universalidade, particularidade ou singularidade - se encontrava ora em destaque, ora esquecido. Segundo Barbier (1985), o momento da universalidade é acentuado a partir de Hegel, pelos filósofos do direito: a Constituição, as Leis, as normas em geral representam a universalidade ou os valores máximos.

O momento da particularidade está presente com o pensamento antropológico, no qual a negação da universalidade se faz imperativo: é a valorização dos sujeitos que, nas condições materiais concretas, negam o instituído. Nas sociedades industriais, mesmo o trabalho assalariado sendo um fenômeno universal, há não-assalariados que o negam como fenômeno total. Para o autor, este seria um exemplo da diferença entre universalidade e totalidade. Isto é importante, pois há correntes teóricas que confundem o momento da universalidade com a totalidade, ou propostas de intervenções organizacionais que se pretendem universais, mas se constituem em totalitárias.

Já o momento da singularidade é realçado com o marxismo e, mais recentemente, pelo movimento institucionalista francês, que questionou tanto o aprisionamento do conceito pelo momento da universalidade, quanto pelo momento da particularidade. Para os marxistas, as instituições são formas singulares, estruturadas por relações de força, nelas em disputa. 
Este artigo assume o conceito de instituição como descrito por Lourau \& Lapassade (1972), ou seja, o conceito de instituição se compõe de três momentos dinâmicos: a universalidade, dada pelo instituído; a particularidade, dada pelo movimento instituinte e a singularidade, dada pela institucionalização. A institucionalização é, portanto, um desses momentos dinâmicos do conceito de instituição, a negação da particularidade e a não-aceitação da universalidade. A institucionalização como a forma singular a partir da qual ela se organiza para atingir certa finalidade.

Busca, ainda, em Barbier (1985) sua perspectiva acerca da evolução histórica da predominância de um dos momentos do conceito de instituição - universalidade, particularidade e segmentaridade - no discurso das principais correntes teóricas das ciências humanas para identificar o significado atribuído ao termo institucionalização e, em um segundo momento, tenta relacioná-los à concepção teórica e às práticas propostas para a institucionalização da avaliação.

Como não é objetivo deste artigo uma revisão dessas correntes, apenas a identificação das possíveis fontes teórico-conceituais que podem estar apoiando as reflexões dos teóricos e as ações que objetivam institucionalizar práticas e concepções, uma revisão sintética pode ser encontrada em autores como Nunes (1989), Domingues (2001), Portocarrero (2002), dentre outros.

\section{A universalidade no pensamento sociológico "clássico"}

Durkheim (2004) e os positivistas sociais vêem a instituição como fato social. Para esse autor, "a instituição, quer se trate de formas sociais, quer de normas ou representações, é anterior e transcendente aos grupos humanos" (LOURAU, 1996, p 105). Na sua concepção, o indivíduo se submete às normas e à disciplina em conseqüência da sua adesão às crenças e sentimentos comuns aos membros de uma sociedade, conceituada como sua "consciência coletiva" (LOURAU; LAPASSADE, 1972). Talcott Parsons, principal artífice da sociologia americana e importante referencial para os estudiosos da sociedade em todo o mundo, almejava construir uma teoria sociológica que incorporasse criticamente as teorias das ciências humanas dominantes até o final do século XX e que desvendasse os mecanismos de interpenetração entre as normas e a ação humana na construção social (LINS; CECILIO, 2007; DOMINGUES, 2001). Ao tentar responder ao problema hobbesiano da ordem, Parsons assume o conceito de "consciência coletiva" de 
Durkheim e o conceito de "superego" de Freud. Segundo Parsons, haveria a introjeção, por parte dos indivíduos, dos padrões culturais normativos da sociedade - as coerções sociais submetendo a ação dos indivíduos, idéia presente no primeiro conceito - e que as regras do comportamento seriam dadas pelas respostas às sanções positivas ou negativas (VIET, 1967), idéia presente no segundo conceito. Assim se daria, portanto, a "transmissibilidade" do sistema cultural. Há aqui, claramente, uma defesa do momento da universalidade no conceito de instituição, do instituído, da predominância das normas introjetadas.

Foi com a hegemonia do pensamento positivista e a expansão do seu referencial teórico e metodológico às ciências sociais que a noção de instituição e a própria prática social defendidas por essa corrente correram o risco de serem transformadas em totalidade, confundindo-a com o momento de universalidade, conforme alertado acima. Lourau \& Lapassade (1972) definem a noção de instituição, para essa corrente, como algo preestabelecido, como uma herança de padrões culturais transmitidos pela educação. Uma totalidade, portanto, ou um vínculo permanente do indivíduo, uma vez ingressado na sociedade. Vínculo este imutável, pois perpetuado pela instituição educação.

Por que é importante ressaltar cada um desses momentos para o propósito deste artigo, de refletir sobre a proposta de institucionalização de maneira geral e, de forma particular, da institucionalização da avaliação nas práticas de saúde? Como já dito, é importante tentar identificar se ela tem potencial para promover as mudanças pretendidas, ou se leva à reprodução das práticas. Na concepção de instituição que estamos apresentando há, expressamente, uma tendência à manutenção do status quo, onde "institucionalizar" representa introjetar regras e normas previamente estabelecidas e que transcendem os indivíduos, portanto perenes e imutáveis.

Felisberto, no artigo citado, fala em uma estratégia de "aculturamento da avaliação". Ora, o significado sociológico de "aculturação", presente nos dicionários, quer revelar o conjunto de fenômenos provenientes do contato direto e contínuo de grupos de indivíduos de culturas diferentes, embora o ideário popular o compreenda como a aceitação ou introjeção de práticas de culturas estranhas à cultura local. Takeda \& Talbot (2006), debatedores do artigo, revelam a preocupação de que a institucionalização da avaliação, conforme proposta, seja entendida como “jeitos de avaliar estranhos”. 
Assim, se a fala institucional que ora se produz na saúde ou em qualquer outra instituição visa a uma institucionalização que prioriza a regra e a norma em detrimento de práticas criativas, o movimento que se pretende inovador poderá se deixar aprisionar pela poderosa estrutura organizacional e virar, simplesmente, mais um gabinete ou quaisquer outras formas instituídas.

O papel da educação, como se viu acima, pode se constituir em potente transmissor de normas e regras estabelecidas, contribuindo para a manutenção do pensamento hegemônico e das mesmas práticas. Assim, há que se cuidar para que estratégias que apontam prioritariamente para as capacitaçôes e a educação permanente como operadores desse fortalecimento não caiam na falácia estruturalfuncionalista, reificadora das práticas e concepções dominantes.

\section{O pensamento fenomenológico e o momento da particularidade}

Para contestar essa visão universalista da sociedade e das instituições que a conformam, alguns importantes autores foram buscar, na sociologia compreensiva de Max Weber e na fenomenologia de Edmund Husserl, fundamentos para compreender a ação humana na construção da sociedade (SCHULTZ, 1979). Alfred Schutz é a melhor expressão de tal esforço de síntese (WAGNER, 1979). Silvermann (1975), a partir das contribuições de Schutz, e escrevendo especificamente sobre as organizaçôes, destaca a ação dos indivíduos na sociedade (e nas organizaçōes) não como participantes de um teatro de títeres, mas orientadas por valores e pelo seu "estoque de conhecimento" e pela sua situação biográfica determinada. Ou seja, como o estoque de conhecimento e a situação biográfica diferem de indivíduo para indivíduo, a sociedade e suas instituições não podem ser trans-históricas, como pregava o movimento da sociologia positivista (DOMINGUES, 2001).

Berger \& Luckmann (1994), também inspirados diretamente em Schutz, buscam explicar a origem do fenômeno da realidade que se apresenta para o indivíduo como objetivada, como um processo de institucionalização de atividades da vida humana. Para esses autores, a institucionalização se dá pela articulação dialética de três momentos fundamentais: i) o da tipificação recíproca de ações habituais por tipos de atores - que constituem as instituições, naturalmente construídas em determinado processo histórico e numa situação social duradoura; ii) essas instituições, agora cristalizadas, são experimentadas como existindo 
independentemente dos indivíduos que as experimentam como possuindo realidade própria - é o momento da objetivação, no qual se argumenta o "é assim que as coisas são"; iii) finalmente, a transmissão desse mundo objetivo às novas geraçôes que o internalizam e o experimentam como dado a priori. Assim, os três momentos se inter-relacionam para institucionalizar atividades e conhecimentos e produzir, continuamente, a realidade.

Os autores, vinculados à fenomenologia, dizem que apreendemos o mundo da vida cotidiana por meio de tipificaçoes: analisamos e nos relacionamos com o outro por meio do que consideramos "atores típicos" que traduzem o perfil padrão que conhecemos de alguns papéis e ações - professor, pai, mãe, trabalhador braçal, funcionário público etc. Naturalmente, nós também somos apreendidos pelos outros atores por meio dessas tipificações. Essas tipificações recíprocas de ações habituais constituem as instituições e, concretamente, as organizações, e são construídas em determinado processo histórico. Uma vez cristalizadas, essas tipificações são experimentadas pelo indivíduo como tendo realidade própria, são objetivadas pelo indivíduo. Essa objetivação, ou o considerar as coisas como dadas, é transmitido às novas geraçôes, que o internalizam e o experimentam como existindo a priori (BERGER; LUCKMANN, 1994). Para esses autores, é assim que se dá a institucionalização de atividades da vida humana.

No que essa "institucionalização" difere da visão anteriormente demonstrada da sociologia positivista? Para os sociólogos fenomenológicos, esses processos não acontecem em ambientes isentos de outros indivíduos; muito pelo contrário, são processos de interação em um mundo intersubjetivo. Há outros indivíduos com estoques de conhecimento e histórias biográficas próprias. A soma das tipificações e dos padrões recorrentes de interação derivados das primeiras é que conforma a estrutura social. Diferente, portanto, da visão positivista e com implicações importantes para nossa reflexão sobre a institucionalização de práticas e saberes.

A investigação fenomenológica concentra-se no campo da experiência pura, e a explicação de quem experimenta o fenômeno depende dessa e de outras vivências, do conhecimento previamente adquirido e do contexto no qual ele ocorre. Perguntar o que é um objeto para diferentes sujeitos com diferentes experiências, conhecimentos e em diferentes contextos deverá trazer diferentes respostas (TÁPIA, 1984). Por outro lado, em um contexto dado e restrito, a experiência comum ou a objetivação das experiências cristalizadas poderá levar a respostas-padrão. 
Neste momento, o foco é colocado na particularidade, onde a subjetividade do indivíduo é sobrevalorizada e com potencial para mudar, a qualquer momento, os rumos da história e das instituições. Não haveria, então, estruturas imutáveis e perenidade das normas: o indivíduo situado no mundo da vida, por meio de suas ações interessadas, produziria/instituiria continuamente a sociedade e as instituições nela contidas.

$\mathrm{Na}$ experiência prática nas organizações de saúde, vê-se com muita freqüência o grande papel que se coloca na capacitação das pessoas e na busca por líderes natos. Aliás, as ditas lideranças das organizaçôes e dos estabelecimentos de saúde, bem como das comunidades, parecem ser os alvos prioritários das capacitações. Esta visão traduz a ênfase que se coloca nos indivíduos como potencialmente transformadores das estruturas.

\section{A análise institucional e a busca da síntese, o momento da singularidade}

O movimento institucionalista francês, representado por autores como René Lourau, Georges Lapassade, Felix Guatarri e Gilles Deleuze, entre outros, propõe uma outra via de análise da sociedade e das instituiçôes, partindo de sua crítica à noção de instituição até então discutida pelos movimentos antecedentes. Afirma a instituição como sendo a forma assumida pela produção e reprodução de relaçóes sociais em um dado modo de produção, como um reflexo da organização das relações de produção nessa sociedade. Nesse sentido se aproxima dos marxistas, criticando-os, porém, por autonomizarem o momento da particularidade ao subestimar a ação recíproca entre superestrutura e infra-estrutura (BARBIER, 1985; LOURAU, 1996).

Para esses institucionalistas, dialeticamente, um momento está contido no anterior e o nega na ação concreta dos indivíduos e das coletividades, ou seja, toda idéia é tão verdadeira quanto sua contrária, desde que encarnada na ação concreta. O movimento institucionalista nega a oposição entre o particular e o geral que oblitera o terceiro momento do conceito de instituição - o momento da singularidade - e principalmente a ação recíproca dos três momentos. Segundo seus autores, com essa oposição se produzem antinomias que só poderiam ser resolvidas pela preponderância dada à estrutura (ou às normas, ao instituído), ou à ação (ao indivíduo, ao instituinte). 
Como já explicitado, essa negação da negação não ocorre para validar a universalidade, mas para encontrar moldes onde o encontro dos dois momentos possa ocorrer. É o momento das formas singulares organizacionais que são necessárias para atingir dado objetivo (a produção de uma mercadoria) ou finalidade (saúde, educação). É o momento da institucionalização (BARBIER, 1985; LOURAU, 1996). Institucionalização, portanto, não significando a introjetação de regras e normas previamente estabelecidas e que transcendem os indivíduos, nem significando o individualismo separado do campo sócio-histórico.

Para Lourau e Lapassade (1972), autonomizar o terceiro momento seria dar ênfase à racionalidade e positividade das formas sociais em detrimento da história, das contradiçóes e da luta de classes, erro imputado aos autores da sociologia das organizações, segundo ambos.

Os conceitos que melhor sintetizam o momento da singularidade ou da institucionalização são os conceitos de segmentaridade e transversalidade largamente utilizados pelos institucionalistas. A segmentaridade é o caráter singular dos grupamentos que a intervenção socianalítica encontra (LOURAU, 2004a), ou seja, os grupamentos, organizaçóes, coletividade étnica ou política, mesmo sendo comunidades de interesses convergentes negadas pelas particularidades de seus membros, não são destruídas por que se reagrupam em uma multidão de grupos singulares que lhes dão unidade.

Transversalidade é um conceito defendido por Guattari (BARBIER, 1985) para contrapor-se aos movimentos da verticalidade, dada pela introjeção das normas nos grupos oficiais e ao da horizontalidade ou informalidade dos grupos em uma organização, defendido pela sociologia fenomenológica. É o entrecruzamento de pertencimentos e referências do coletivo constituído,

não apenas porque eles sejam múltiplos (os pertencimentos e referências), também porque a colaboração e coabitação criam um consenso de fato, uma horizontalidade que atravessa a verticalidade de pertencimentos e referências internas e externas, assim como a horizontalidade é atravessada pela verticalidade (LOURAU, 2004b, p. 132).

A transversalidade seria a comunicação máxima entre os diferentes níveis e em diferentes sentidos. Os dois conceitos são utilizados em conjunto para caracterizar a singularidade na organização: esta forma de materialização dos enunciados das instituições seria composta por inúmeros segmentos atravessados por sentimentos de pertencimentos que rompem as divisões dicotômicas entre dominados/dominantes; 
explorados/exploradores e instituído/instituinte, na medida em que eles congregam dialeticamente os opostos. Este momento de integração em formas singulares de organização, de gestão, de administração e de funcionamento assegura a implicação institucional de cada indivíduo na organização, na sociedade (BARBIER, 1985).

Outro importante conceito da análise institucional aplicada à prática social é o de analisador: "aquilo que permite revelar a estrutura da organização, provocá-la, forçá-la a falar" ou "o surgimento das contradiçôes até então ocultas ou não mencionadas", é o cutucar o não-dito que se quer investigar (BARBIER, 1985). Nesse sentido, a função de analisador pode ser desempenhada pelo analista que funciona como um provocador do imaginário institucional ou por acontecimentos simbólicos que surgem em decorrência direta ou não da sua atuação.

Então, qual o significado dos conceitos acima abordados para a institucionalização que se discute? $\mathrm{Na}$ visão dos institucionalistas franceses, a noção de instituição, composta pelos três momentos descritos, convivendo dialeticamente nas organizações, possibilita um modelo dinâmico de institucionalização que não se confunde com a organização vista como totalidade ou com o paradigma grupal dos psicossociólogos. A segmentaridade e a transversalidade presentes nas organizaçôes - que materializam as opções das instituiçóes - revelam que a institucionalização ou o momento de negação da negação reflete tanto as opções institucionais, quanto as contradições da convivência das normas com a ação instituinte dos grupos ou sujeitos. Esta é síntese dialética do terceiro momento, o da singularidade. Ela nos permite ver as organizações como formas materiais singulares, distantes, portanto, de entes transistóricos e imutáveis. A institucionalização como um processo permanente, enfim.

\section{À luz dos conceitos formulados, como conduzir o movimento pela institucionalização de práticas da saúde para que ele seja potencialmente transformador?}

Ao longo do texto foram apresentadas as noções de instituição vinculadas às principais correntes de pensamento das ciências sociais: i) o positivismo sociológico, que concebe a instituição transcendente aos grupos humanos e a institucionalização como a introjeção, pelos agrupamentos humanos, das normas previamente estabelecidas; ii) a fenomenologia sociológica, que credita aos grupos humanos a potência transformadora das instituições, por meio de suas ações interessadas e a institucionalização como resultado da interação dos indivíduos nas organizações; 
iii) a análise institucional, herdeira e crítica do marxismo, que pensa a instituição como um reflexo da organização das relações de produção em uma dada sociedade e concebe a institucionalização um dos momentos da instituição ou formas singulares que congregam os dois outros momentos, da universalidade e da particularidade. São formas que podem ser observadas na segmentaridade dos grupos dentro de uma organização, não podendo a institucionalização ser confundida com a organização, pois em uma organização podem conviver diversos movimentos de institucionalização ou agrupamentos que se segmentam para enfrentar disputas no contexto desses dispositivos concretos.

Há que se ressaltar a contribuição das ciências humanas para a compreensão das dinâmicas sociais mais amplas e dos grupos em particular e que, para a compreensão destes, muitos dos seus conceitos foram reapropriados pelos estudiosos das organizaçôes, administradores e avaliadores, num processo dialético de construção do vocabulário dos diferentes campos de conhecimento. Eles se tornam, portanto, instrumentos particulares da linguagem desses grupos. No entanto, como processo de construção histórica e social, a linguagem traduz a visão de mundo e a forma de inserção social desses grupos, assim como a finalidade das ações que imprimem: de reprodução ou de transformação social. Dito isto, ressaltamos que os autores deste artigo procuraram construir um conceito de institucionalização na perspectiva de uma intervenção sobre a realidade.

Assim, o(s) movimento(s) pela institucionalização de práticas trará consigo a visão de mundo dos seus idealizadores e os determinantes do contexto no qual se inserem. Viu-se que a institucionalização constitui um processo histórico e social, concretamente povoado por atores que disputam interesses, portanto não linear ou perene. Assim, ações intempestivas, práticas verticalizadas e autoritárias e expectativas imediatistas devem ser olhadas com cuidado.

É importante ter sempre claro que, como processo histórico de construção social, a instituição saúde é revelada no modo de produção em saúde, na prática concreta dos profissionais que atuam em suas organizações ou estabelecimentos. Portanto, a institucionalização da avaliação em saúde deve se propor a construir uma nova prática, a provocar uma mudança na prática do fazer saúde atual e não apenas na prática de avaliar ou não avaliar.

Encarar e superar as tipificações que foram construídas socialmente e que carregamos na interação com os outros atores (funcionário público, avaliador, 
avaliado, esferas de gestão) - o ministério que pensa e as secretarias que executam - são passos difíceis, mas necessários. Buscar os demais profissionais como cogestores do movimento de institucionalização da avaliação em saúde que se desencadeia pode ser uma estratégia facilitadora do processo.

É fundamental não encarar a institucionalização em saúde com o objetivo de torná-la parte da norma. As cristalizações e as açôes criativas acontecem como um movimento ininterrupto no processo de construção social. Partir com objetivo de normatizar uma prática desvia a finalidade que se acredita ser a de criar movimentos de institucionalização, como se viu anteriormente.

Identificar os segmentos organizacionais que estejam se constituindo ou possam se constituir em movimentos de institucionalização da prática para a promoção de alianças, para a promoção de pactos de co-gestão, pode ser um caminho eficaz. Eles não devem ser identificados apenas nos grupos formalmente constituídos grupos de avaliação, núcleos de acompanhamento, supervisão, auditoria ou outros, dependendo da prática que se procura institucionalizar - mas também fora deles. Esses grupos podem estar apenas reproduzindo o modo de produção e a prática em saúde atual. É, aliás, o que se vê freqüentemente nas ações de "capacitação" ou "educação continuada" que se preocupam com a reprodução das tipificações e não permitem criar movimentos instituintes.

Não se vê, sem importância, a visão de instituição como organização, ou forma material. Essa visão esconde as segmentaridades que existem nesse dispositivo concreto, por ser vista como totalidade. Ao se considerar instituição como organização, esquecese de buscar construir movimentos de institucionalização dentro das organizações e priorizam-se os momentos de universalidade, priorizando-se normas e padrões.

Finalmente, no que tange à prática de avaliação, é importante considerá-la como campo de intervenção e de análise, não esquecendo que ela está inserida em um contexto mais amplo e que não são apenas o Ministério da Saúde e as instituições de ensino e pesquisa que intervêm e buscam explicar a realidade. Não existe uma secretaria única, uma organização única, assim como não existe um ministério único. Existem infinidades de intervenções e explicações da realidade, e projetos em disputa estão aí presentes. Essa dinâmica nas organizaçôes produz singularidades, portanto a institucionalização da avaliação em saúde, que identifica e respeita essa multiplicidade de segmentos que se agrupam e desagrupam para atingir certas finalidades, pode contribuir para o movimento contínuo de transformação das práticas em saúde. 


\section{Referências}

BARBIER, René. A pesquisa-ação na instituição educativa. Rio de Janeiro: J. Zahar; 1985. 280p.

BAREMBLIT, Gregório F. Compêndio de análise institucional e outras correntes: teoria e prática. Rio de Janeiro: Rosa dos Tempos, 1996. 235p.

BERGER, Peter; LUCKMANN, Thomas. A construção social da realidade. Petrópolis: Vozes, 1994. 247p.

BRASIL. Ministério da Saúde. Avaliação da Atenção Básica em Saúde: caminhos da institucionalização. Brasília: MS; 2005.

. Ministério da Saúde. Departamento de Ciência e Tecnologia. Avaliação de tecnologias em Saúde: institucionalização das açōes no Ministério da Saúde. Rev Saúde Pública, São Paulo, v. 40, n. 4, p. 743-747, 2006.

CONILL, E. M. Sobre a importância da parcimônia, do diálogo e da continuidade para a institucionalização da avaliação da atenção básica. Rev Ciência Saúde Coletiva, Rio de Janeiro, v. 11, n. 3, p. 564-566, 2006.

DOMINGUES, José M. teorias sociológicas do século XX. Rio de Janeiro: Civilização Brasileira; 2001. 110 p.

. A sociologia de Talcott Parsons. Niterói: Eduff; 2001. 106p.

DURKHEIM, Émile. As regras do método sociológico. São Paulo: Martin Claret; 2004. 155p.

FELISBERTO, E. Da teoria à formulação de uma Política Nacional de Avaliação em saúde: reabrindo o debate. Rev Ciência Saúde Coletiva, v. 11, n. 3, p. 553-565, 2006.

HARTZ, Zulmira M. A. Institucionalizar e qualificar a avaliação: outros desafios para a atenção Básica. Rev Ciência Saúde Coletiva, v. 7, n. 3, p. 419-21, 2002.

Institutionalizing the evaluation of health programs and policies in France: cuisine internationale over fast food and sur mesure over ready-made. Cad Saúde Pública, v. 15, n. 2, p. 229-59, 1999.

LAPASSADE, George, Grupos, organizaçôes e instituiçôes. Rio de Janeiro: Francisco Alves, 1989.316 p.

LINS, Auristela M.; CECILIO, Luiz Carlos de O. Campos de intervençôes organizacionais: a contribuição de autores das Ciências Humanas para uma leitura crítica das propostas de gestão das organizações de saúde. Interface - Comunic., Saúde, Educação. Botucatu, 2007. Disponível em: <http://www.interface.org.br/arquivos/aprovados/artigo20.pdf>. Acesso em: 08 set. 2007.

LOURAU, René. A análise institucional. Petrópolis: Vozes, 1996. 293p.

. O instituinte contra o instituído. In: ALTOÉ, S. (Org.). René Lourau: analista institucional em tempo integral. São Paulo: Hucitec; 2004a. 287p.

. Uma apresentação da análise institucional. In: ALTOÉ, S. (Org.). René Lourau: analista institucional em tempo integral. São Paulo: Hucitec; 2004b. 287p. 
LOURAU, René; LAPASSADE, George. Chaves da sociologia. Rio de Janeiro: Civilização Brasileira, 1972. 203 p.

MATUS, Carlos R. Politica, planicicación y gobierno. Washington, DC, 1987.

NUNES, Everardo D. (Org.). Juan César Garcia: pensamento social em saúde na América Latina. São Paulo: Cortez; 1989. 238p.

PISCO, L. A. A avaliação como instrumento de mudança. Rev Ciência Saúde Coletiva, v. 11, n. 3, p. 566-568, 2006.

PORTOCARRERO, V. (Org.). Filosofia, história e sociologia das ciências: abordagens contemporâneas. Rio de Janeiro: Fiocruz, 2002.

SCHULTZ, Alfred. Fundamento da fenomenologia. In: WAGNER, H. R. (Org.). Fenomenologia e relaçôes sociais. Rio de Janeiro: Zahar; 1979.319p.

SILVERMANN, David. Teoría de las organizaciones. Buenos Aires: Ediciones Neuva Visíon; 1975. 300p.

TAKEDA, S.; TALBOT, Y. Avaliar, uma responsabilidade. Rev Ciência Saúde Coletiva, v. 11, n. 3, p. 569-571, 2006.

TANAKA, O. Y. Caminhos alternativos para uma institucionalização da avaliação em saúde. Rev Ciência Saúde Coletiva, v. 11, n. 3, p. 571-572, 2006.

TÁPIA, Luiz E. R. Método em fenomenologia. In: DICHTCHEKENIAN, J. M.; DICHTCHEKENIAN, M. F. S. F. (Orgs.). Temas fundamentais de fenomenologia. São Paulo: Moraes, 1984. p. 69-74.

TEIXEIRA, C. F. Institucionalizando a prática de avaliação em saúde: significado e limites. Rev Ciência Saúde Coletiva, v. 11, n. 3, p. 572-574, 2006.

VIET, J. Métodos estruturalistas nas ciências sociais. Rio de Janeiro: Tempo Brasileiro; 1967.360p. WAGNER, Helmut R. (Org.). Fenomenologia e relaçôes sociais: textos escolhidos de Alfred Schutz. Rio de Janeiro: Zahar Editores, 1979. 319p. 


\section{Abstract}

The institutionalization speech of health practices: A reflection based on the approach of the Human Sciences

This paper aims to promote reflections on the movement to institutionalize health practices evaluation: can it lead to the intended changes or may it reproduce old practices? To answer these questions, it was necessary to resort to the aid of Human Sciences mainly the authors who study social institutions. These authors based their theories on Positivistic sociology, on sociological phenomenology and on the precepts of the French institutionalism movement. Following their lines of thought, this paper is intended to further understand the concept of institution and institutionalization present in those social schools. Based on the theoretical framework which encourages this text, the authors suggest some special attention be placed on actions that support the movement for health evaluation institutionalization.

> Key words: Evaluation; institutionalization; health services; health policies, Social Sciences. 